\title{
Immunohistochemical analysis of Metadherin in proliferative and cancerous breast tissue
}

\author{
Peng Su' ${ }^{1}$ Qinghui Zhang ${ }^{* 1}$ and Qifeng Yang*2
}

\begin{abstract}
Background: Metadherin (MTDH) has been reported to be associated with cancer progression in various types of human cancers including breast cancer. Whether MTDH contributes to carcinogenesis of breast cancer is still unknown. In the present study, we investigated the expression of MTDH in normal, UDH (usual ductal hyperplasia), ADH (atypical ductal hyperplasia), DCIS (ductal carcinoma in situ) and invasive cancer to explore the possible role of MTDH for breast cancer carcinogenesis.
\end{abstract}

Methods: Immunohistochemistry was employed on paraffin sections of surgical removed breast samples.

Results: The immunohistochemical results showed almost no staining in normal tissue, moderate staining in ADH and UDH, intense MTDH stains in DCIS and cancer. Statistical analysis demonstrated significant different MTDH expression between proliferative and cancerous breast lesions $(p<0.001)$. MTDH was positively correlated with the histological differentiation of DCIS ( $p=0.028$ ). In breast cancer, statistical analysis revealed a significant correlation between MTDH expression with patients' age $(p=0.042)$, ER status $(p=0.018)$ and p53 status $(p=0.001)$. We also examined the effect of MTDH on cell proliferation in DCIS and cancer, and we found that MTDH overexpression was significantly correlated with high Ki67 index ( $p=0.008$ and $p=0.036$, respectively).

Conclusions: MTDH overexpression could be identified in proliferative breast lesions and may contribute to breast cancer progression.

\section{Background}

The intraductal proliferative lesions of breast are a group of cytologically and architecturally diverse proliferations, typically originating from the terminal duct-lobular unit and confined to the mammary duct-lobular system. According to WHO Working Group on Pathology and Genetics of Tumors of the Breast, intraductal proliferative lesions have been divided into usual ductal hyperplasia (UDH), atypical ductal hyperplasia (ADH), flat epithelia atypia (FEA), and ductal carcinoma in situ (DCIS). Clinical studies have indicated UDH, ADH and DCIS in the breast are related to different levels of risk for the subsequent development of invasive carcinoma. The risk factors of subsequent invasive breast carcinoma are 1.5 times for $\mathrm{UDH}$, 4-5 times for $\mathrm{ADH}$, and 8-10 times for

*Correspondence: qinghuizhang@yahoo.com, qifengy@gmail.com

1 Department of Pathology, Qilu Hospital, Shandong University School of Medicine, Ji'nan, China

2 Department of Breast Surgery, Qilu Hospital, Shandong University School of Medicine, Ji'nan, China

Full list of author information is available at the end of the article
DCIS, respectively[1]. Increased interest is to identify factors driving disease progression from $\mathrm{UDH}, \mathrm{ADH}$, DCIS to invasive cancer.

Metadherin (MTDH[2], also known as astrocyte elevated gene-1(AEG-1)[3,4], and Lysine-rich CEACAM-1associated protein(Lyric) $[5,6]$ was originally identified as an oncogene induced in primary human fetal astrocytes infected with human immunodeficiency virus type 1(HIV-1) or treated with HIV envelope glycoprotein(gp120) or tumor necrosis factor- $\alpha(\mathrm{TNF}-\alpha)[3,7]$. Human MTDH/AEG-1 mRNA encodes a 582 amino acid protein with a calculated molecular mass of $64 \mathrm{kDa}$ and p19.3. It promotes tumourigenesis, metastases and chemoresistance. Several signaling pathways have been found to be associated with the expression of $\mathrm{MTDH} /$ AEG-1, including Ha-ras, PI3K/Akt, NF- $\mathrm{kB}$ and Wnt/ $\beta$ catenin[8]. For example, MTDH could cooperate with oncogenic Ha-ras to increase soft agar colony formation of nontumorigenic immortalized melanocytes and HeLa cells[4], also it serves as a downstream target gene of Haras in regulating proliferation and transforming activi-

๑ 2010 Su et al; licensee BioMed Central Ltd. This is an Open Access article distributed under the terms of the Creative Commons Attri:-1 1 Central bution License (http://creativecommons.org/licenses/by/2.0), which permits unrestricted use, distribution, and reproduction in any
medium, provided the original work is properly cited. 
ties[9]. By activating the NF-kB pathway, MTDH could increase anchorage-independent growth and invasiveness of HeLa cells[10]. MTDH also activates cell survival pathways through PI3K/Akt signaling[11]. It has been found that MTDH ubiquitously expresses in numerous cell types, elevated levels have also been observed in some human tumor types, such as breast cancer, prostate cancer, hepatocellular carcinoma, neuroblastoma, esophageal squamous cell carcinoma (ESCC) and non-small cell lung cancer (NSCLC)[12-16]. Expression of MTDH could augment anchorage-independent growth. Overexpression of MTDH could inhibit apoptosis induced by serum starvation in immortalized primary human fetal astrocytes(PHFA). Upregulation of MTDH increased lung metastasis of breast cancer cell, as well as migration and invasion of glioma cells. All these studies suggest that MTDH plays important roles in the oncogenesis of these tumors. Besides the function of oncogenesis, MTDH was also found to be a lipopolysaccharide(LPS)-responsive gene and involved in LPS-induced inflammatory response via NF- $\mathrm{KB}$ activation[17].

Although previous studies found that MTDH could mediate lung metastasis of breast cancer[2], serve as a prognostic marker for progression and overall patient survival[13,18], whether MTDH involves in the progression of breast precancerous lesions to cancer is still unknown. In the present study, we focused on elucidating the role of $\mathrm{MTDH}$ in the progression of precancerous lesions to breast cancer.

\section{Methods}

\section{Patients and Tissue samples}

This study was conducted on a total of 249 paraffinembedded breast samples, which were histopathologically diagnosed at department of pathology of Qilu Hospital of Shandong University from 2007 to 2009. The intraductal proliferative lesions included 29 cases of UDH (without atypia), 14 cases of $\mathrm{ADH}, 37$ cases of DCIS including 15 low grade, 7 intermediate grade and 15 high grade. There were 162 cases of invasive ductal carcinoma. Normal breast tissues $(n=7)$ from reduction mammoplasty specimens were used as a control group. For the use of these clinical materials for research purposes, prior patient content and approval from the Institutional Research Ethics Committee were obtained. All the diagnoses were made following the Pathology and Genetics of Tumors of Breast of World Health Organization Classification of Tumors[1] and were made by two pathologists. Clinicopathologic classification and staging were determined according to the American Joint Committee on Cancer criteria[19].

\section{Immunohistochemistry}

The streptavidin-peroxidase-biotin (SP) immunohistochemical method was performed to study altered pro- tein expression in 249 paraffin-embedded breast tissues. In brief, paraffin-embedded specimens were cut into 4$\mu \mathrm{m}$ sections and baked at $60^{\circ} \mathrm{C}$ for $60 \mathrm{~min}$. The sections were deparaffinized with xylenes and rehydrated. Sections were submerged into EDTA antigenic retrieval buffer and microwaved for antigenic retrieval, and then cooled at room temperature for 20 minutes. The sections were treated with $3 \%$ hydrogen peroxide in methanol to quench the endogenous peroxidase activity, followed by incubation with normal serum to block nonspecific binding. Rabbit anti-MTDH (1:400; Zymed) was incubated with the sections overnight at $4^{\circ} \mathrm{C}$; the second antibody was from SP reagent kit (Zhongshan Biotechnology Company, Beijing, China). After washing, the tissue sections were treated with biotinylated anti-rabbit secondary antibody, followed by further incubation with streptavidin-horseradish peroxidase complex. Stained with diaminobenzidine (DAB), the sections were counterstained with hematoxylin. For negative controls, the rabbit anti-MTDH antibody was replaced with PBS.

\section{Evaluation of Immunohistochemical Staining}

The stained slides were reviewed and scored independently by two observers blinded to the patients' information, and the scores were determined by combining the proportion of positively stained tumor cells and the intensity of staining. Tumor cell proportion was scored as follows:0 (no positive tumor cells); 1 ( $\leq 20 \%$ positive tumor cells); 2 (21-50\% positive tumor cells); 3 (51-70\% positive tumor cells) and 4 (> 70\% positive tumor cells). Staining intensity was graded according to the following criteria: 0 (no staining); 1 (weak staining = light yellow); 2 (moderate staining = yellow brown) and 3 (strong staining = brown). Staining index (SI) was calculated as the product of staining intensity score and the proportion of positive tumor cells. Using this method of assessment, we evaluated MTDH expression in intraductal proliferative lesions to cancer by determining the SI, with scores of 0 , $1,2,3,4,6,9$ or 12 . The optimal cutoff value for high and low expression level was identified: an SI score of $\geq 4$ was used to define tumors with high MTDH expression, and an SI score of $\leq 3$ was used to indicate none or low MTDH expression.

\section{Statistical Analysis}

Analyses were performed using the statistical software package SPSS 13.0 (SPSS, Chicago, IL). The chi-square test or Fisher's exact test were used to evaluate the correlation between MTDH expression and the clinicopathologic characteristics if appropriate. We evaluated the linear-by-linear association from normal, UDH, $\mathrm{ADH}$, DCIS to cancer lesion. Bivariate correlations between study variables were calculated by Spearman's rank correlation coefficients. Differences were considered statistically significant for $p$ values $<0.05$. 


\section{Results}

Expression of MTDH in UDH, ADH and DCIS

A positive stain for MTDH was defined as brown stain observed in the cytoplasm (Figure 1). There was no MTDH overexpression identified in normal breast tissue.
In the proliferative lesions, overexpression of MTDH protein was expressed in $7 / 29(24.14 \%)$ cases of UDH, 4/ 14(28.57\%) cases of ADH and 27/37(72.97\%) cases of DCIS. Furthermore, 90/162(55.56\%) cases of invasive breast cancer showed MTDH overexpression. The differ-

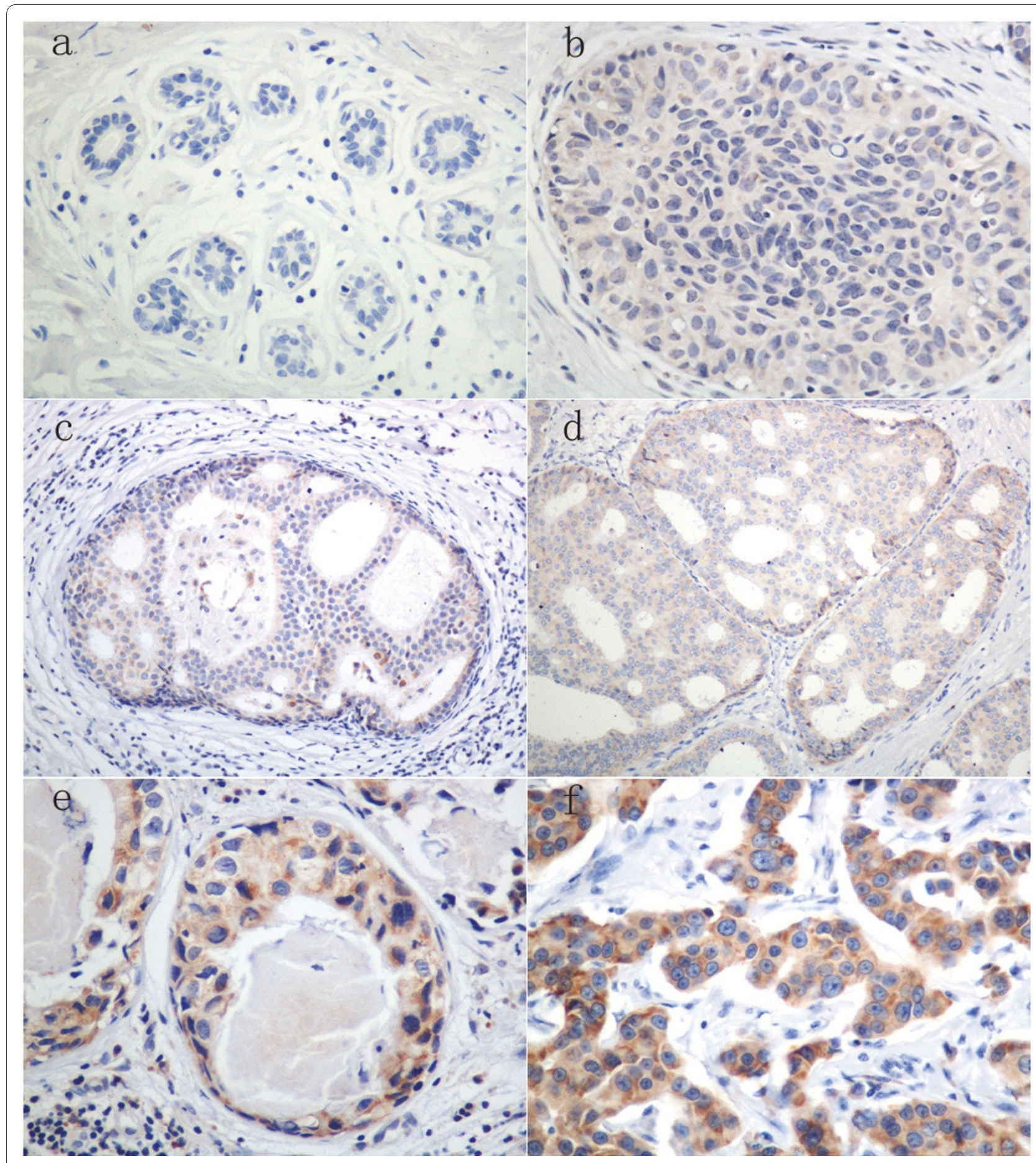

Figure 1 Expression of MTDH by immunohistochemistry in breast precancerous lesions and cancer. AEG-1staining was mainly localized in the cytoplasm of cells. a. normal tissue; b. usual ductal hyperplasia (UDH); c. atypical ductal hyperplasia (ADH); d. low grade ductal carcinoma in situ (DCIS); e. high grade ductal carcinoma in situ(DCIS); f. breast cancer. 
ence of expression between them was significant tested by linear-by-linear association $(p<0.001)$ (Table 1$)$.

\section{Relationship of MTDH expression with the status of ER, PR, ErbB-2 and Ki67 in DCIS}

There was no significant difference between expression of MTDH and expression levels of universal biological factors such as ER, PR, and ErbB-2 in DCIS. In contrast, statistical analyses indicated that the correlation between MTDH and Ki67 expression was significant $(p=0.008)$ (Table 2), which was further confirmed by Spearman correlation analysis $(\mathrm{r}=0.471, p=0.003)$. We also found the expression in histological differentiation was significant $(p=0.028)$ and the expression difference between the high grade and low grade DCIS was also significant $(p=$ 0.035), Spearman correlation of MTDH expression levels to them were $0.379(p=0.021)$ and $0.452(p=0.012)$, respectively. These results suggest that MTDH is overexpressed in highly proliferative DCIS cells and high grade lesions.

\section{Relationship of MTDH overexpression with the clinical features of invasive breast cancer}

As show in the Table 3, MTDH expression was strongly correlated with the patients' age ( $p=0.042)$, Ki67 status $(p=0.036)$, ER status $(p=0.018)$ and $\mathrm{p} 53$ status $(p=$ 0.001 ), whereas it was not associated with other clinical characteristics. Spearman correlation analysis was further preformed to confirm the correlation between MTDH expression and patients' age, Ki67, ER and p53 status, which were $-0.16(p=0.042), 0.164(p=0.037)$, $0.185(p=0.018)$ and $0.261(p=0.001)$ respectively.

\section{Discussion}

With the introduction of mammographic screening, incidence of the precursor lesions has dramatically increased. Pathological and clinical evidence suggests that different intraductal proliferative lesions have different magnitudes of risk for the subsequent development of invasive ductal carcinoma. One of the key challenges is to identify any independent molecular attribute to the transition or as a biomarker to monitor the progression.

Recently, many reports have demonstrated that oncoprotein MTDH is linked to the biological processes such as cancer cell survival, proliferation, apoptosis, migration, metastasis and chemoresistence. MTDH has been also found to be upregulated in several types of human cancers, including breast cancer, prostate cancer, glioblastoma, hepatocellular carcinoma and esophageal carcinoma. All these findings have implicated the role of the overexpression of MTDH in the initiation and progression of cancer. Especially in breast cancer, several reports have found that MTDH could increase lung metastasis of breast cancer cell[2], promote chemoresistance and metastasis by 8q22 genomic gain[18], associate with poor overall survival and promote the proliferation of breast cancer cells through downregulation of tumor suppressor and cell-cycle inhibitor genes, $\mathrm{p} 21^{\mathrm{Cip} 1}$ and p27 Kip1, possibly via Akt/FOXO1 signaling[13,20]. To investigate whether the expression of MTDH is found in the intraductal proliferative lesions and the upregulation of MTDH is also related to the process of breast oncogenesis, we performed our studies.

In the present study, for the first time, we found that MTDH is low or no expressed in normal cases, but with the intraductal proliferative lesions progression, the expression level and intensity are higher and stronger gradually. This suggests that MTDH might represent a novel indicator for the prognosis of breast lesions and might play a role in the development and progression of breast lesions. We found high expressed MTDH in $72.97 \%$ of DCIS, but in $55.56 \%$ of invasive ductal carcinoma. This may suggest that MTDH plays a more important role in initiation of ductal carcinoma. We also examined the correlation between MTDH expression and common proliferative marker Ki67 in DCIS and breast cancer. In cancer, the correlation between MTDH and Ki67 is significant $(p=0.036)$, which is in consistent with the result of Li et al[20]. We first found that the correlation is also significant $(p=0.008)$ in DCIS. MTDH is

Table 1: Expression of MTDH in normal tissues, UDH, ADH, DCIS and breast cancer

\begin{tabular}{|c|c|c|c|c|c|}
\hline \multirow[t]{2}{*}{ Categories } & \multirow[t]{2}{*}{ n } & \multicolumn{2}{|c|}{ MTDH expression } & & \multirow[b]{2}{*}{$p$-value } \\
\hline & & Low expression & High expression & & \\
\hline normal & 7 & 7 & 0 & $0.00 \%$ & $<0.001$ \\
\hline UDH & 29 & 22 & 7 & $24.14 \%$ & \\
\hline $\mathrm{ADH}$ & 14 & 10 & 4 & $28.57 \%$ & \\
\hline DCIS & 37 & 10 & 27 & $72.97 \%$ & \\
\hline cancer & 162 & 72 & 90 & $55.56 \%$ & \\
\hline
\end{tabular}

$p$ value stands for linear-by-linear association 
Table 2: Relationship between MTDH and DCIS

\begin{tabular}{|c|c|c|c|c|}
\hline \multirow[t]{2}{*}{ Characteristics } & \multirow[t]{2}{*}{$\mathbf{n}$} & \multicolumn{2}{|c|}{ MTDH expression } & \multirow[b]{2}{*}{$p$-value } \\
\hline & & Low expression & High expression & \\
\hline \multicolumn{5}{|l|}{ ER } \\
\hline negative & 7 & 0 & 7 & 0.155 \\
\hline positive & 30 & 10 & 20 & \\
\hline \multicolumn{5}{|l|}{ PR } \\
\hline negative & 9 & 0 & 9 & 0.079 \\
\hline positive & 28 & 10 & 18 & \\
\hline \multicolumn{5}{|l|}{ ErbB-2 } \\
\hline negative & 28 & 10 & 18 & 0.079 \\
\hline positive & 9 & 0 & 9 & \\
\hline \multicolumn{5}{|l|}{ Ki67 } \\
\hline $\operatorname{low}(\leq 10 \%)$ & 19 & 9 & 10 & 0.008 \\
\hline $\operatorname{high}(>10 \%)$ & 18 & 1 & 17 & \\
\hline \multicolumn{5}{|c|}{ Histological differentiation } \\
\hline L\&I-DCIS & 22 & 9 & 13 & $0.028^{*}$ \\
\hline H-DCIS & 15 & 1 & 14 & \\
\hline
\end{tabular}

* $p$-value between low grade DCIS and high grade DCIS is 0.035

overexpressed in highly proliferative lesions of breast cancer and DCIS. In DCIS, we also found that the expression difference between low grade and high grade ( $p=$ $0.035)$. All these might suggest that increased cell proliferation associated with overexpressed MTDH may contribute to the development and progression of breast lesions.

In malignant glioma cells, overexpressed $\mathrm{MTDH}$ is located predominantly in the nucleus, where it interacts with the p65 subunit of NF- $\mathrm{kB}$ and $\mathrm{CBP}$, thus activating NF- $\mathrm{kB}$ signaling[10,21]. MTDH also regulates production of LPS-induced proinflammatory mediators via enhanced NF- $\mathrm{kB}$ activation[17]. The transcription factor nuclear factor $\kappa \mathrm{B}(\mathrm{NF}-\mathrm{\kappa B})$ regulates the expression of a wide variety of genes involved in cellular events such as inflammation, immune response, proliferation and apoptosis[22]. But in our study, we found MTDH mainly localized in the cytoplasm of intraductal proliferative lesions and cancer cells, there is very little nuclear staining. This result is the same with $\mathrm{Li}$ et al and $\mathrm{Hu}$ et al[13,18], in nonsmall cell lung cancer, hepatocelluar carcinoma and ESCC the expression also is found mainly in the cytoplasm. So in the proliferative lesions and cancer of breast, MTDH might play an important role, but the exact mechanism is still unknown and need more studies to demonstrate it.

MTDH can induce serum-independent cell growth by blocking serum starvation-induced apoptosis through
PI3K-Akt signaling pathways and downstream signaling molecules of Akt including GSK3b-Myc, Bad, MDM2p53 and p21/mda-6, which cause inhibition of caspase activities[11]. In our present study, we found the correlation between MTDH and p53 expression in protein level using immunohistochemical staining $(p=0.001)$. In invasive cancer, we also found MTDH overexpression was associated with several other poor prognostic features, such as younger patient age $(p=0.042)$ and negative estrogen receptor status $(p=0.018)$. However, our results do not correlate with from findings of Li et al. [13], they reported that there was no correlation found between MTDH expression and patient age or expression levels of estrogen receptors, progesterons receptors. Tumorigenic potential of MTDH was supported by two observations, elevated expression in subsets of cancer cell lines and promotion of anchorage independent growth of immortalized melanocytes and astrocytes[4]. In our study, we found that MTDH expressed in UDH, ADH, DCIS, but the positive cases and intensity were different. (In DCIS, especially in high grade DCIS, the rate of high expression of $\mathrm{MTDH}$ is $93.3 \%$; in $\mathrm{ADH}$, the rate is $28.57 \%$; in $\mathrm{UDH}$, the rate is $24.14 \%$ ).

\section{Conclusions}

Our findings suggest that the overexpression of MTDH may be a useful indicator for intraductal proliferation disease development and progression. Its overexpression is 
Table 3: correlation between MTDH expression and the clinicopathologic characteristics of breast cancer patients

\begin{tabular}{|c|c|c|c|c|}
\hline \multirow[t]{2}{*}{ Characteristics } & \multirow[t]{2}{*}{$\mathbf{n}$} & \multicolumn{2}{|c|}{ MTDH expression } & \multirow[b]{2}{*}{$p$-value } \\
\hline & & Low expression & High expression & \\
\hline \multicolumn{5}{|l|}{ Age(y) } \\
\hline$\leq 50$ & 66 & 23 & 43 & 0.042 \\
\hline$>50$ & 96 & 49 & 47 & \\
\hline \multicolumn{5}{|l|}{ Grade } \\
\hline$|\&| \mid$ & 118 & 56 & 62 & 0.206 \\
\hline III & 44 & 16 & 28 & \\
\hline \multicolumn{5}{|l|}{ TNM stage } \\
\hline I & 51 & 25 & 26 & 0.607 \\
\hline ॥ & 72 & 32 & 40 & \\
\hline III & 39 & 15 & 24 & \\
\hline \multicolumn{5}{|l|}{ Tumor size } \\
\hline $\mathrm{T} \leq 2 \mathrm{~cm}$ & 80 & 39 & 41 & 0.276 \\
\hline $\mathrm{T}>2 \mathrm{~cm}$ & 82 & 33 & 49 & \\
\hline \multicolumn{5}{|l|}{ Lymph node metastasis } \\
\hline No & 88 & 40 & 48 & 0.778 \\
\hline N1 & 74 & 32 & 42 & \\
\hline \multicolumn{5}{|l|}{ Expression of Ki67 } \\
\hline $\operatorname{low}(\leq 10 \%)$ & 35 & 21 & 14 & 0.036 \\
\hline $\operatorname{high}(>10 \%)$ & 127 & 51 & 76 & \\
\hline \multicolumn{5}{|l|}{ Expression of $\mathrm{p} 53$} \\
\hline low & 96 & 53 & 43 & 0.001 \\
\hline high & 66 & 19 & 47 & \\
\hline \multicolumn{5}{|l|}{ ER } \\
\hline negative & 66 & 22 & 44 & 0.018 \\
\hline positive & 96 & 50 & 46 & \\
\hline \multicolumn{5}{|l|}{$\mathrm{PR}$} \\
\hline negative & 64 & 25 & 39 & 0.265 \\
\hline positive & 98 & 47 & 51 & \\
\hline \multicolumn{5}{|l|}{ ErbB-2 } \\
\hline negative & 130 & 61 & 69 & 0.201 \\
\hline positive & 32 & 11 & 21 & \\
\hline
\end{tabular}

correlated with the proliferation in DCIS and cancer. Further investigation on the molecular mechanism of MTDH involvement in the process of the intraductal proliferative lesions is warranted, especially on the PI3K/Akt and NF- $\mathrm{kB}$ signaling pathway.

Competing interests

The authors declare that they have no competing interests.

\section{Authors' contributions}

PS did the immunohistochemical analysis. QZ reviewed all the pathological slides. QY designed the study and analyzed the data. All authors read and approved the final manuscript

\section{Acknowledgements}

The study is supported by Program for New Century Excellent Talents in University, Key Project of Chinese Ministry of Education (No. 108080), National Natural Science Foundation of China (No. 30772133) and Independent Innovation Foundation of Shandong University (IIFSDU, 2009JQ007) to Dr. Yang Q.

\section{Author Details}

'Department of Pathology, Qilu Hospital, Shandong University School of Medicine, J'nan, China and 2Department of Breast Surgery, Qilu Hospital, Shandong University School of Medicine, Ji'nan, China

Received: 24 May 2010 Accepted: 18 June 2010 Published: 18 June 2010 


\section{References}

1. Tavassoli FA, Devilee P: Intraductal proliferative lesions. Pathology and genetics of tumors of the breast and female genetic organs. Lyon: International Agency for Research on Cancer (IARC) Press; 2003.

2. Brown DM, Ruoslahti E: Metadherin, a cell surface protein in breast tumors that mediates lung metastasis. Cancer Cell 2004, 5(4):365-374.

3. Su ZZ, Kang DC, Chen Y, Pekarskaya O, Chao W, Volsky DJ, Fisher PB: Identification and cloning of human astrocyte genes displaying elevated expression after infection with HIV-1 or exposure to HIV-1 envelope glycoprotein by rapid subtraction hybridization, $\mathrm{RaSH}$. Oncogene 2002, 21(22):3592-3602

4. Kang DC, Su ZZ, Sarkar D, Emdad L, Volsky DJ, Fisher PB: Cloning and characterization of HIV-1-inducible astrocyte elevated gene-1, AEG-1. Gene 2005, 353(1):8-15.

5. Sutherland HG, Lam YW, Briers S, Lamond Al, Bickmore WA: 3D3/lyric: a novel transmembrane protein of the endoplasmic reticulum and nuclear envelope, which is also present in the nucleolus. Exp Cell Res 2004, 294(1):94-105.

6. Britt DE, Yang DF, Yang DQ, Flanagan D, Callanan H, Lim YP, Lin SH, Hixson DC: Identification of a novel protein, LYRIC, localized to tight junctions of polarized epithelial cells. Exp Cell Res 2004, 300(1):134-148.

7. Su ZZ, Chen Y, Kang DC, Chao W, Simm M, Volsky DJ, Fisher PB: Customized rapid subtraction hybridization (RaSH) gene microarrays identify overlapping expression changes in human fetal astrocytes resulting from human immunodeficiency virus-1 infection or tumor necrosis factor-alpha treatment. Gene 2003, 306:67-78.

8. Hu G, Wei Y, Kang Y: The multifaceted role of MTDH/AEG-1 in cancer progression. Clin Cancer Res 2009, 15(18):5615-5620

9. Lee SG, Su ZZ, Emdad L, Sarkar D, Fisher PB: Astrocyte elevated gene-1 (AEG-1) is a target gene of oncogenic $\mathrm{Ha}$-ras requiring phosphatidylinositol 3-kinase and c-Myc. Proc Natl Acad Sci USA 2006, 103(46): 17390-17395

10. Emdad L, Sarkar D, Su ZZ, Randolph A, Boukerche H, Valerie K, Fisher PB. Activation of the nuclear factor kappaB pathway by astrocyte elevated gene-1: implications for tumor progression and metastasis. Cancer Res 2006, 66(3):1509-1516.

11. Lee SG, Su ZZ, Emdad L, Sarkar D, Franke TF, Fisher PB: Astrocyte elevated gene-1 activates cell survival pathways through PI3K-Akt signaling. Oncogene 2008, 27(8):1114-1121.

12. Kikuno N, Shiina H, Urakami S, Kawamoto K, Hirata H, Tanaka Y, Place RF, Pookot D, Majid S, Igawa M, et al:: Knockdown of astrocyte-elevated gene-1 inhibits prostate cancer progression through upregulation of FOXO3a activity. Oncogene 2007, 26(55):7647-7655.

13. Li J, Zhang N, Song LB, Liao WT, Jiang LL, Gong LY, Wu J, Yuan J, Zhang HZ, Zeng MS, et al: Astrocyte elevated gene-1 is a novel prognostic marker for breast cancer progression and overall patient survival. Clin Cancer Res 2008, 14(11):3319-3326.

14. Lee SG, Jeon HY, Su ZZ, Richards JE, Vozhilla N, Sarkar D, Van Maerken T, Fisher PB: Astrocyte elevated gene-1 contributes to the pathogenesis of neuroblastoma. Oncogene 2009

15. Song L, Li W, Zhang H, Liao W, Dai T, Yu C, Ding X, Zhang L, Li J: Overexpression of AEG-1 significantly associates with tumour aggressiveness and poor prognosis in human non-small cell lung cancer. J Pathol 2009, 219(3):317-326.

16. Yu C, Chen K, Zheng H, Guo X, Jia W, Li M, Zeng M, Li J, Song L: Overexpression of Astrocyte Elevated Gene-1 (AEG-1) Is Associated with Esophageal Squamous Cell Carcinoma (ESCC) Progression and Pathogenesis. Carcinogenesis 2009, 30(5):894-901.

17. Khuda II, Koide N, Noman AS, Dagvadorj J, Tumurkhuu G, Naiki Y, Komatsu T, Yoshida T, Yokochi T: Astrocyte elevated gene-1 (AEG-1) is induced by lipopolysaccharide as toll-like receptor 4 (TLR4) ligand and regulates TLR4 signalling. Immunology 2009, 128(1 Suppl):e700-706.

18. Hu G, Chong RA, Yang Q, Wei Y, Blanco MA, Li F, Reiss M, Au JL, Haffty BG, Kang Y: MTDH activation by $8 \mathrm{q} 22$ genomic gain promotes chemoresistance and metastasis of poor-prognosis breast cancer. Cancer Cell 2009, 15(1):9-20.

19. Greene FL, Page DL, Fleming ID: Breast Cancer in AJCC Cancer Staging Handbook. TNM Classification of Malignant Tumors. 6th edition. New York: Springer Verlag; 2002.

20. Li J, Yang L, Song L, Xiong H, Wang L, Yan X, Yuan J, Wu J, Li M: Astrocyte elevated gene-1 is a proliferation promoter in breast cancer via suppressing transcriptional factor FOXO1. Oncogene 2009, 28(36):3188-96

21. Sarkar D, Park ES, Emdad L, Lee SG, Su ZZ, Fisher PB: Molecular basis of nuclear factor-kappaB activation by astrocyte elevated gene-1. Cancer Res 2008, 68(5):1478-1484.

22. Bharti AC, Aggarwal BB: Nuclear factor-kappa B and cancer: its role in prevention and therapy. Biochem Pharmacol 2002, 64(5-6):883-888.

doi: $10.1186 / 1746-1596-5-38$

Cite this article as: Su et al., Immunohistochemical analysis of Metadherin in proliferative and cancerous breast tissue Diagnostic Pathology 2010, 5:38

\section{Submit your next manuscript to BioMed Central and take full advantage of:}

- Convenient online submission

- Thorough peer review

- No space constraints or color figure charges

- Immediate publication on acceptance

- Inclusion in PubMed, CAS, Scopus and Google Scholar

- Research which is freely available for redistribution
C) Biomed Central 